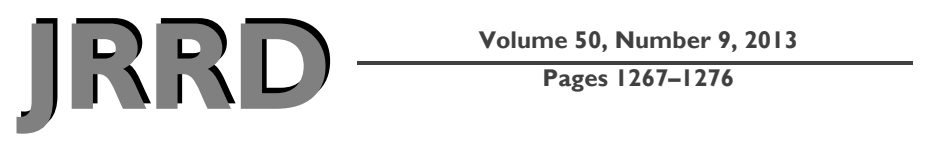

\title{
Determinants of postsurgical discharge setting for male hip fracture patients
}

\author{
Matthew L. Maciejewski, PhD; ${ }^{1-2 *}$ Tiffany A. Radcliff, PhD; ${ }^{3-5}$ William G. Henderson, PhD; ${ }^{3,5}$ Diane Cowper \\ Ripley, PhD; ${ }^{6}$ W. Bruce Vogel, PhD; ${ }^{6}$ Elizabeth Regan, MD, PhD; ${ }^{5,7}$ Evelyn Hutt, MD $^{3,5}$ \\ ${ }^{1}$ Center for Health Services Research in Primary Care, Durham Department of Veterans Affairs (VA) Medical Center, \\ Durham, NC; ${ }^{2}$ Division of General Internal Medicine, Department of Medicine, Duke University, Durham, NC; \\ ${ }^{3}$ University of Colorado Health Outcomes Program, Aurora, CO; ${ }^{4}$ Department of Health Policy and Management, \\ School of Rural Public Health, Texas A\&M Health Science Center, College Station, TX; ${ }^{5}$ VA Eastern Colorado \\ Healthcare System, Denver, CO; ${ }^{6}$ North Florida/South Georgia VA Health System, Gainesville, FL; ${ }^{7}$ National Jewish \\ Health, Denver, $\mathrm{CO}$
}

\begin{abstract}
Veterans hospitalized for hip fracture repair may be discharged to one of several rehabilitation settings, but it is not known what factors influence postsurgical discharge setting. The purpose of the study was to examine the patient, facility, and market factors that influence the choice of postsurgical discharge setting. Using a retrospective cohort design, we linked 11,083 veterans who had hip fracture surgeries in a Department of Veterans Affairs (VA) hospital from 1998 to 2005 as assessed by the VA National Surgical Quality Improvement Program dataset with administrative data. The factors associated with five postdischarge settings were analyzed using multinomial logistic regression. We found that few veterans $(0.8 \%)$ hospitalized for hip fracture were discharged with home health. Higher proportions of veterans were discharged to a nursing home $(15.4 \%)$, to outpatient rehabilitation (18.8\%), to inpatient rehabilitation $(16.9 \%)$, or to home $(48.2 \%)$. Patients were more likely to be discharged to nonhome settings for VA-provided rehabilitation if they had total function dependence, had American Society of Anesthesiologists class 4 or 5, had surgical complications prior to discharge, or lived in counties with lower nursing home bed occupancy rates. Future research should compare postsurgical and longer-term morbidity, mortality, and healthcare utilization across these rehabilitation settings.
\end{abstract}

Key words: admission, discharge, hip fracture, home care, inpatient rehabilitation, Medicare, nursing home, outpatient rehabilitation, treatment, veterans.

\section{INTRODUCTION}

Changes in Medicare payment incentives to increase efficiency have reduced postacute care (PAC) use [1-2]. However, there are competing concerns that reduced utilization and changing care sites may induce adverse events [3]. Continued uncertainty regarding best venues for rehabilitative care for most clinical diagnoses compounds the problem. The Department of Veterans Affairs (VA) Veterans Health Administration (VHA) offers a comprehensive spectrum of rehabilitation care for veterans

\footnotetext{
Abbreviations: $\mathrm{ASA}=$ American Society of Anesthesiologists, $\mathrm{CPT}=$ Current Procedural Terminology, FSOD $=$ Functional Status Outcomes Database, GEM = geriatric evaluation and management, $\mathrm{OR}=$ odds ratio, $\mathrm{PAC}=$ postacute care, $\mathrm{PPS}=$ prospective payment system, SQDUG $=$ Surgical Quality Data Use Group, VA = Department of Veterans Affairs, VASQIP = VA National Surgical Quality Improvement Program, VHA = Veterans Health Administration.

*Address all correspondence to Matthew L. Maciejewski, PhD; Center for Health Services Research in Primary Care (152), Durham VA Medical Center, 508 Fulton St, Durham, NC 27705. Email: matthew.maciejewski@va.gov
}

http://dx.doi.org/10.1682/JRRD.2013.02.0041 
eligible for surgical treatment in VA facilities, so examining patterns of PAC setting choice for a single type of surgery provides unique data to inform clinical and policy discussions.

Veterans with hip fracture are a clinically important subset of patients who often require rehabilitation care following surgery. Approximately 1,200 hip fracture surgeries are performed in VHA annually, while many more veterans have hip fracture surgeries under Medicare auspices. Veterans with hip fractures tend to be younger, in poorer health, and predominantly male compared with Medicare patients with hip fracture repairs [4-5].

Many hospitalized veterans require postacute rehabilitation services following hospitalization. Studies have examined rehabilitation settings for stroke, lower-limb amputation, and polytrauma [6-7], but no studies have examined the postacute discharge patterns of veterans with hip fracture. There is some evidence that increased adherence to VHA guidelines for stroke rehabilitation is associated with better patient outcomes [6], but there are no guidelines for hip fracture. Extensive research of PAC settings for a variety of common conditions, including hip fracture, in the Medicare program [8-14] has noted an increased use of inpatient rehabilitation over other settings when prospective payment for hip fracture was implemented [13-14]. In 2005, 24 percent of beneficiaries were discharged to inpatient rehabilitation after hip fracture, 62 percent were discharged to skilled nursing facilities, 9 percent were discharged to home, and the remainder were discharged to long-term care settings or hospice [14].

Prior Medicare research examined use of PAC according to local availability of services or changing payment structures [1-2]. VHA services are fairly consistent across geographic areas, but inpatient rehabilitation availability may vary according to competing demands for these services. Most VHA facilities that offer acute inpatient care also provide intensive inpatient rehabilitation, home health, or services analogous to skilled nursing facilities or nursing homes. Patients may also be discharged from VHA care to receive rehabilitation from a non-VA provider. However, assigning patients to these various rehabilitation settings depends on the patients' clinical needs, competing demands for VHA's rehabilitation resources, and the veterans' ability to access non-VA (e.g., Medicare) rehabilitation resources. This study explored the factors that affect choice of VHA rehabilitation setting after acute hip fracture repair procedures.
Patient characteristics and payment incentives in VHA differ greatly from Medicare and other insurers, so PAC use likely differs in important ways.

\section{METHODS}

\section{Sample and Data}

Data for this retrospective study were obtained from the VA National Surgical Quality Improvement Program (VASQIP), other VA administrative claims data from VHA, and the Area Resource File. VASQIP is a quality assessment program within VA Surgical Service whose data collection methods have been described in detail elsewhere [15-16]. Briefly, trained nurses collect information preoperatively, intraoperatively, and $30 \mathrm{~d}$ postoperatively with a standardized protocol for most major surgical operations performed at VA hospitals. Information collected at the time of surgery includes age, sex, ethnicity, preoperative comorbidities, laboratory values, and prefracture functional status measures. Operative data include Current Procedural Terminology (CPT) codes, operative times, anesthesia technique, American Society of Anesthesiologists (ASA) class, whether the operation was emergent, and wound class. Postoperative outcomes include $30 \mathrm{~d}$ mortality, morbidity, and 20 different predefined postoperative complications.

We selected all male patients during fiscal years 1998 to 2005 who were identified through VASQIP data as having had CPT codes 27235, 27236, 27244, or 27245, indicating skeletal traction or open or closed treatment of a hip fracture. We also included CPT codes 27125 (hemiarthroplasty) and 27130 (arthroplasty) when the patient had a diagnosis code consistent with an acute hip fracture (ICD-9 [International Statistical Classification of Diseases and Related Health Problems-9] codes 820.x, $820.2 x$, or 820.8 ). We selected the first hip fracture repair procedure for patients who had multiple operations. VASQIP records were matched on the basis of unique patient identifiers to other VHA records, including a hospital discharge file. Our initial sampling criteria identified 15,528 unique patients with VA hip fracture surgeries.

We excluded patients if they were not alive $5 \mathrm{~d}$ after discharge $(n=281)$, were women $(n=600)$, were missing geographic information $(n=104)$, died prior to rehabilitation $(n=1,814)$, or were missing data for at least 
one key variable used in the statistically modeling $(n=$ $1,646)$. The final sample included 11,083 veterans.

\section{Outcomes and Explanatory Variables}

The outcome was the setting to which the veteran was discharged immediately after his hip fracture hospitalization according to five possible PAC settings: inpatient rehabilitation, nursing home, or three variants of discharge to community (home health, home with VHA outpatient rehabilitation, or home without VA-paid rehabilitation). Discharge disposition was defined on the basis of VASQIP data linked to VHA inpatient data files, VHA data files of non-VA hospitalizations, VHA nursing home data files, and the VHA Functional Status Outcomes Database (FSOD). Nearly all veterans showed evidence of a physical therapy assessment during their initial hospitalization, so we defined discharge disposition in a stepwise fashion.

A veteran was defined as having hospital-based rehabilitation if any of the following were true: (1) an FSOD record indicated acute or continuum care; (2) the discharge bed section code following the index inpatient stay indicated a VHA non-nursing home admission to a hospital unit for rehabilitation medicine, geriatric evaluation and management (GEM) rehabilitation, or rehabilitation medicine observation; or (3) a hospital admission followed the index admission and was associated with a principal diagnosis of V57.xx (care involving use of rehabilitation procedures).

A veteran was defined as having nursing home rehabilitation if any of the following were true: (1) an FSOD record indicated subacute care; (2) the discharge bed section code following the index inpatient stay indicated a VHA nursing home admission followed the index admission in a hospital unit for rehabilitation medicine, GEM rehabilitation, or rehabilitation medicine observation; (3) a VHA extended care admission followed the index admission and was associated with a principal diagnosis of V57.xx; or (4) a VHA extended care admission followed the index admission and was associated with a procedure code of 93.xx.

A veteran was defined as discharged to community with home health rehabilitation if a home health visit was recorded following the index admission. A veteran was defined as discharged to community with outpatient rehabilitation if there was an outpatient visit recorded following the index admission that occurred in an outpatient clinic providing rehabilitation, physical therapy, or occu- pational therapy or an outpatient visit had a diagnostic or procedure code indicative of rehabilitation, physical therapy, or occupational therapy. Veterans were defined as discharged to community having no VA-paid rehabilitation of any kind if no previously listed rehabilitation services were indicated.

There is little prior published work to guide unique predictors of PAC use in the VHA system. A summary of findings from studies of PAC use in Medicare indicated that using any PAC services is related to increasing age, that use is more limited for those who are married [2,1721], and that comorbid conditions that require intensive monitoring (e.g., dementia/Alzheimer disease) also increase PAC use.

\section{Analysis}

We compared demographic and clinical variables using $t$-tests or chi-square tests. Given that PAC setting outcomes had five unordered categories (inpatient rehabilitation, nursing home, home health, other outpatient, home), we estimated a multinomial logistic regression that incorporates multiple outcome categories into a single-choice model for joint estimation. The general model form is (Equation (1)) -

$$
\operatorname{Ln} Y_{(m \mid b)(X)}=\operatorname{Ln}[\operatorname{Pr}(y=m \mid x) / \operatorname{Pr}(y=b \mid x)]
$$

The probability that a patient used setting of type $m$ given explanatory variable $x$ is represented as $\operatorname{Pr}(y=m \mid x)$, which is presented relative to the reference category probability that the patient did not have any observed rehabilitation care in VA $(\operatorname{Pr}(y=b \mid x))$. This would include cases in which rehabilitation services were provided by another payer (e.g., Medicare) or not provided at all to the patient. The reference group was set to discharge directly to home. Following Buntin et al. [2], we used the methods of Lane and Nelder [22] to calculate standardized predictions from the estimated model coefficients.

Regression models adjusted for age, sex, race (white, nonwhite), marital status (married, previously married, never married), military service-related disability, and rural residence. Patient health status variables were adjusted for Charlson comorbidity categories, baseline functional status (independent, partially dependent, totally dependent), ASA class, admission source (community vs institutional setting), days from admission to surgery, length of hospital stay, and the type of hip fracture 
repair (CPT code). Higher Charlson and ASA scores indicate greater patient risk or sickness. To account for the availability of non-VA PAC resources, we also adjusted for the number of inpatient rehabilitation beds and the nursing home bed occupancy rate in each veteran's county of residence from the Area Resource File. We also controlled for fixed effects by geographic region as defined by Veterans Integrated Service Network. Human subject approvals were obtained from the local Institutional Review Boards of each coauthor, and authorization to use VASQIP data was obtained from the VA Surgical Quality Data Use Group (SQDUG) of Patient Care Services in VA Central Office, Washington, DC.

\section{RESULTS}

We found that 48.2 percent $(n=5,340)$ of the 11,083 veterans were discharged to home without VA-paid rehabilitation, 18.8 percent $(n=2,079)$ were discharged to home with outpatient rehabilitation, 16.9 percent $(n=$ $1,874)$ were discharged to inpatient rehabilitation, 15.4 percent $(n=1,704)$ were discharged to a nursing home, and 0.8 percent $(n=86)$ were discharged to home with home healthcare (Table 1).

Unadjusted patient characteristics and market characteristics were statistically significant between patients discharged to different settings (Table 1). Patients admitted from the community were more likely to be discharged to other outpatient settings or to home health $(p<$ 0.001 ), while patients living in rural areas were more likely to be discharged to home without VA-paid rehabilitation $(p<0.001)$. Patients discharged to inpatient rehabilitation had the longest length of stay for their hip fracture $(24 \mathrm{~d})$, while patients discharged to a nursing home or to home health had shorter lengths of stay (14 d and $16 \mathrm{~d}$, respectively) $(p<0.001)$. Finally, veterans discharged to VHA inpatient rehabilitation lived in counties with more inpatient rehabilitation beds, while veterans discharged to outpatient rehabilitation or to home lived in counties with fewer inpatient rehabilitation beds and lower nursing home occupancy rates $(p<0.001)$.

\section{ADJUSTED ANALYSES}

Adjusted results from the multinomial logistic regression (Table 2) indicated that patients were more likely to be discharged to inpatient rehabilitation (compared with discharge directly to home) if they had total functional dependence (odds ratio $[\mathrm{OR}]=1.78,1.53-$ 2.07 ), higher surgical risk (ASA class $4 / 5$ : $\mathrm{OR}=1.23$, $1.10-1.37)$, or more hospital days preceding surgery $(\mathrm{OR}=$ $1.04,1.03-1.04)$. Patients were less likely to be discharged to inpatient rehabilitation if they were white $(\mathrm{OR}=$ $0.82,0.71-0.94)$, had greater comorbidity burden $(\mathrm{OR}=$ $0.94,0.92-0.97)$, had ASA class 3 (OR $=0.88,0.81-$ $0.96)$, were admitted from the community $(\mathrm{OR}=0.62$, $0.54-0.72)$, had a longer length of stay $(\mathrm{OR}=0.97,0.97$ $0.98)$, or lived in counties with more inpatient rehabilitation beds $(\mathrm{OR}=0.29,0.15-0.55)$ or higher nursing home bed occupancy rates $(\mathrm{OR}=0.84,0.80-0.89)$.

Patients were more likely to be discharged to a nursing home if they were nonelderly $(\mathrm{OR}=1.27,1.10-1.45)$, had total functional dependence $(\mathrm{OR}=1.22,1.02-1.46)$, had a higher Charlson score $(\mathrm{OR}=1.03,1.00-1.06)$, had more days prior to surgery $(\mathrm{OR}=1.05,1.04-1.06)$, or had surgical complications prior to discharge $(\mathrm{OR}=2.37$, 1.94-2.90). They were less likely to be discharged to a nursing home if they were age $85 \mathrm{yr}$ or over $(\mathrm{OR}=0.80$, 0.68-0.96), were white $(\mathrm{OR}=0.81,0.69-0.96)$, had a longer length of stay $(0.96,0.95-0.96)$, or lived in counties with more inpatient rehabilitation beds $(\mathrm{OR}=0.17$, 0.08-0.35) or higher nursing home bed occupancy rates $(\mathrm{OR}=0.78,0.73-0.82)$.

Patients were more likely to be discharged to home health if they had total functional dependence $(\mathrm{OR}=$ $1.72,1.03-2.86)$, had more days prior to surgery $(\mathrm{OR}=$ $1.03,1.00-1.07)$, or had complications from surgery prior to discharge $(\mathrm{OR}=3.07,1.81-5.19)$. Patients were less likely to be discharged to home health if they had a longer length of stay $(\mathrm{OR}=0.97,0.95-0.99)$ or lived in a rural area $(\mathrm{OR}=0.32,0.13-0.75)$.

Patients were more likely to be discharged for outpatient rehabilitation if they were age 75 to $84 \mathrm{yr}(\mathrm{OR}=$ $1.12,1.00-1.25)$, had partial functional dependence $(\mathrm{OR}=$ $1.15,1.02-1.31)$, had greater military service-related disability $(\mathrm{OR}=1.35,1.09-1.68)$, had greater operative risk (ASA class 4/5: OR $=1.31,1.14-1.50$ ), had more days prior to surgery $(\mathrm{OR}=1.06,1.05-1.07)$, were admitted from the community $(\mathrm{OR}=1.20,1.01-1.43)$, or had surgical complications prior to discharge $(\mathrm{OR}=2.27,1.84$ 2.81). Patients were less likely to be discharged for outpatient rehabilitation than to home if they were white $(\mathrm{OR}=$ $0.83,0.70-0.99)$, had a longer length of stay $(\mathrm{OR}=0.95$, 
Table 1.

Descriptive comparison of patients by initial postacute rehabilitation settings.

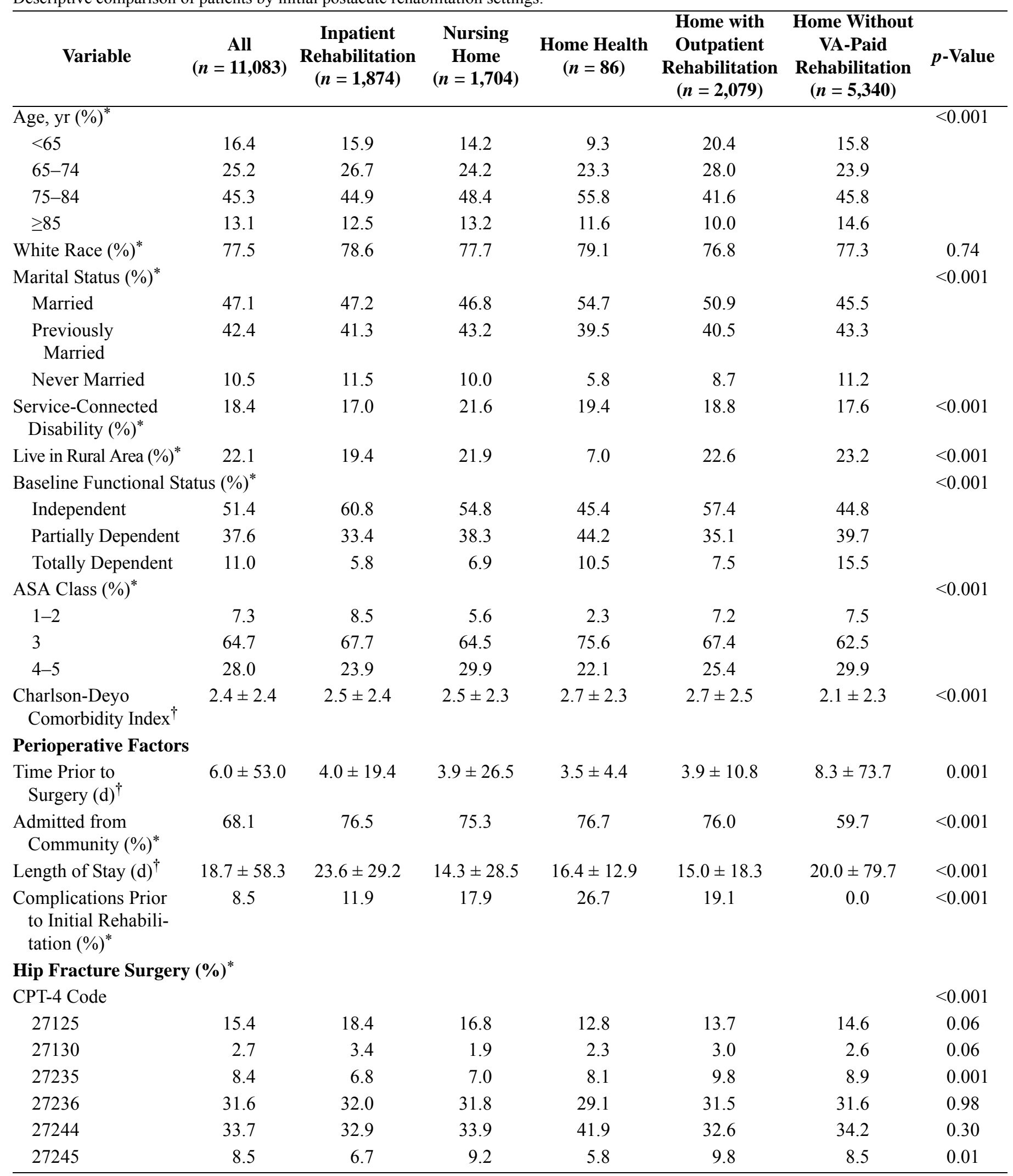


JRRD, Volume 50, Number 9, 2013

Table 1. (cont)

Descriptive comparison of patients by initial postacute rehabilitation settings.

\begin{tabular}{|c|c|c|c|c|c|c|c|}
\hline Variable & $\begin{array}{c}\text { All } \\
(n=11,083)\end{array}$ & $\begin{array}{l}\text { Inpatient } \\
\text { Rehabilitation } \\
\quad(n=1,874)\end{array}$ & $\begin{array}{l}\text { Nursing } \\
\text { Home } \\
(n=1,704)\end{array}$ & $\begin{array}{l}\text { Home Health } \\
\qquad(n=86)\end{array}$ & $\begin{array}{c}\text { Home with } \\
\text { Outpatient } \\
\text { Rehabilitation } \\
(n=2,079)\end{array}$ & $\begin{array}{l}\text { Home Without } \\
\text { VA-Paid } \\
\text { Rehabilitation } \\
\quad(n=5,340)\end{array}$ & $p$-Value \\
\hline \multicolumn{8}{|c|}{ County Rehabilitation Resources } \\
\hline $\begin{array}{l}\text { Inpatient Rehabilita- } \\
\text { tion Beds }\end{array}$ & $97.2 \pm 116.4$ & $124.2 \pm 148.0$ & $115.7 \pm 126.6$ & $89.0 \pm 98.7$ & $83.8 \pm 106.2$ & $87.2 \pm 101.3$ & $<0.001$ \\
\hline \multicolumn{8}{|c|}{$\begin{array}{l}\text { Note: Mean } \pm \text { standard deviation unless percentage indicated. } \\
{ }^{*} \text { Chi-square test reported for categorical variables. } \\
{ }^{\dagger} F \text { statistic from analysis of variance model reported for continuous variables. } \\
\text { ASA = American Society of Anesthesiologists, CPT- } 4=\text { Current Procedural Terminology-4, VA = Department of Veterans Affairs. }\end{array}$} \\
\hline
\end{tabular}

Table 2.

Odds ratios from multinomial logistic regression on initial postacute settings. $N=11,803$.

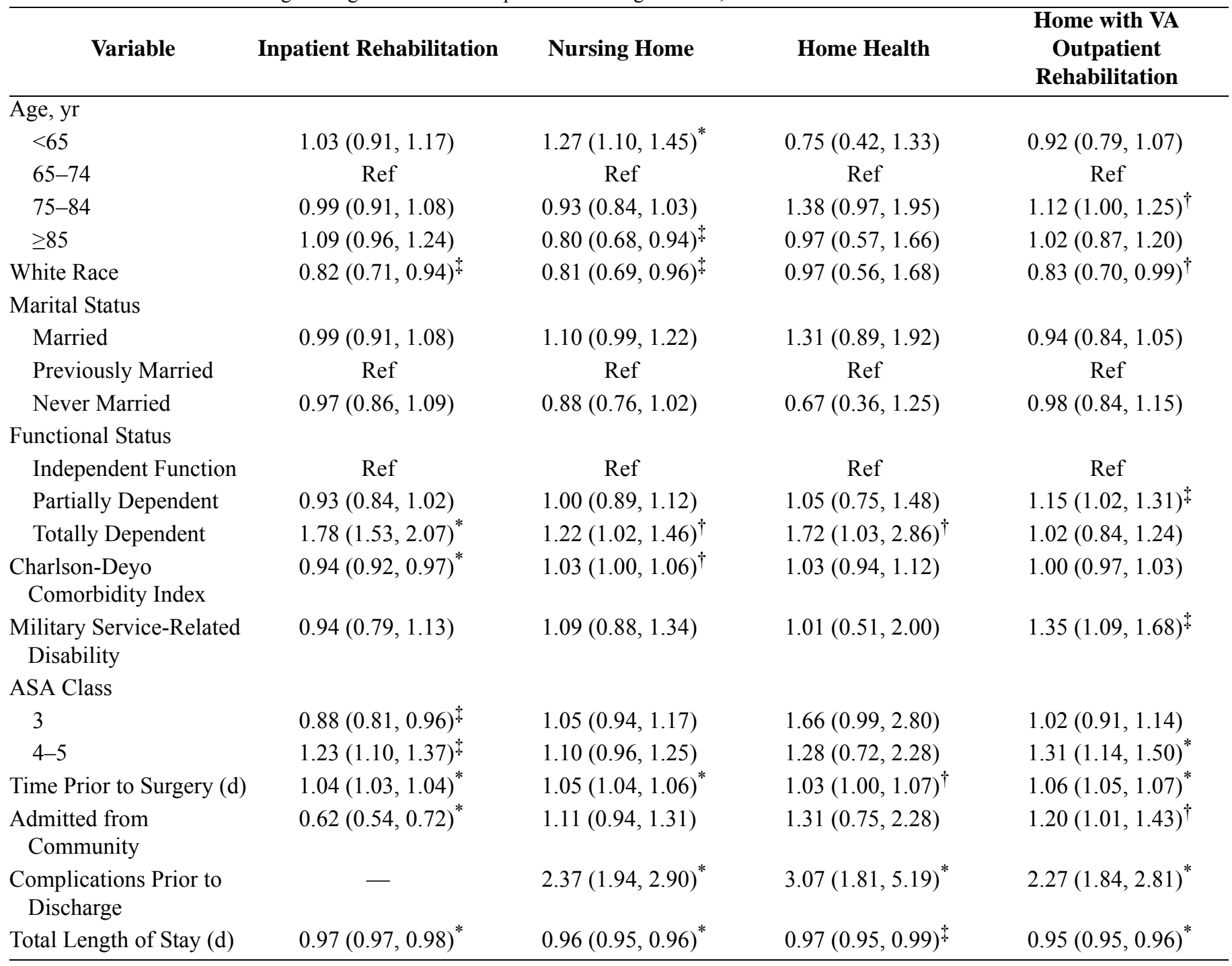


Table 2. (cont)

Odds ratios from multinomial logistic regression on initial postacute settings. $N=11,803$.

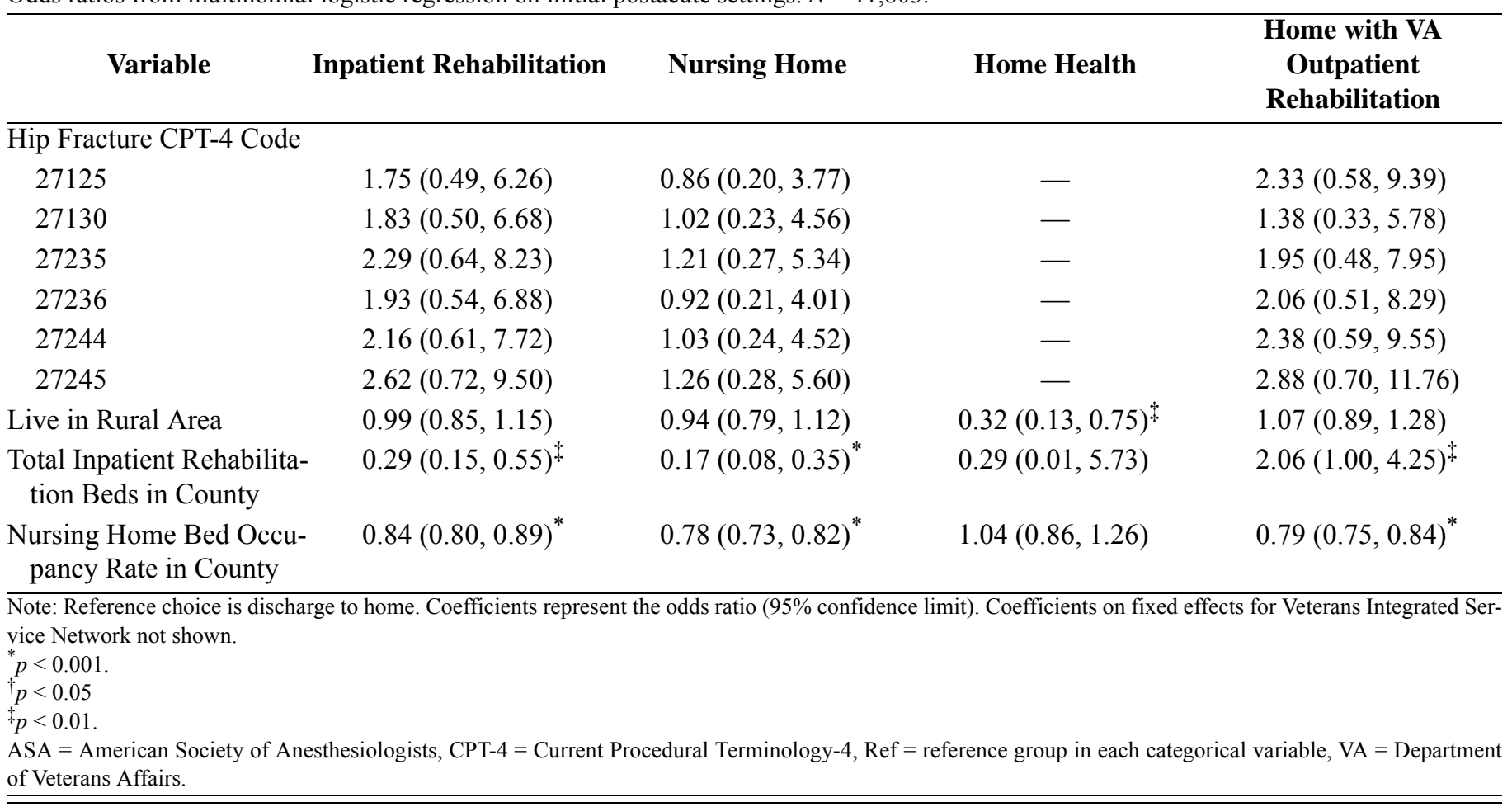

0.95-0.96), or lived in counties with higher nursing home bed occupancy rates $(\mathrm{OR}=0.79,0.75-0.84)$.

\section{DISCUSSION}

In this examination of choice of discharge setting for veterans hospitalized for hip fracture, we were surprised to find that nearly half of the sample was discharged directly home after hospitalization (compared with $9 \%$ of Medicare beneficiaries discharged to home in 2005 [14]). This may have occurred because these patients either went to a Medicare provider or needed no additional care postdischarge given an average length of stay of $19 \mathrm{~d}$. We were also surprised to observe that patients with higher Charlson comorbidity scores were less likely to be discharged to inpatient rehabilitation. Otherwise, patients were more likely to be discharged to these nonhome settings if they had total function dependence, had high ASA class scores, had surgical complications, or lived in counties with lower nursing home bed occupancy rates. Thus, the most vulnerable veterans were not sent directly home, but were provided inpatient care.
As expected, surgical complications were the most significant predictor of discharge setting, but the availability of community resources were also important predictors. This suggests that VHA discharge planners consider VHA and non-VA resources when determining placement after hip fracture, particularly for patients who have complications. We were surprised to see that patients with longer hospital lengths of stay were less likely to receive rehabilitation from the four VHA sources, which may be due to provision of initial rehabilitation prior to discharge and less need for rehabilitation after discharge. VHA routinely provides initial rehabilitation prior to discharge because it takes an integrated approach to patient management as the nation's largest integrated care system.

These results contrast with similar analyses of Medicare beneficiaries with hip fracture because a lower proportion of veterans were discharged to nursing homes $(15 \%$ vs $58 \%)$ and more were discharged to home $(68 \%$ vs $9 \%-14 \%$ ) [23]. Both patient and system factors may explain these differences. Veterans admitted for hip fracture repair tend to be younger than Medicare beneficiaries and may have stronger preference for communitybased options. The financial incentives also differ between 
VA and Medicare. Under the initial inpatient prospective payment system (PPS), Medicare providers were paid a fixed amount for each inpatient hospital stay, which created an incentive to discharge patients for intensive rehabilitation care soon after intensive orthopedic procedures such as hip fracture repair. With 25 percent spending increases for PAC each year, in 1997 Medicare implemented PPS for PAC as well, which has changed the types of PAC that patients receive. However, there is little evidence of significant changes in PAC utilization or care settings for patients with serious conditions such as hip fracture [1]. In contrast, the VA operates under a global budget as a single payer, so payment incentives have a smaller effect on care patterns. Instead, VA can coordinate postsurgical rehabilitation care within the VA system or in concert with other payers to best meet the clinical needs of veterans.

Several limitations must be acknowledged. First, the limited sample size of veterans discharged to home health may have limited power to detect clinically meaningful differences in some covariates. Second, our data did not capture rehabilitation settings under non-VA auspices (e.g., Medicare), which may have been used by a subgroup of cases assigned to the "home" setting. Despite these limitations, this analysis of determinants of PAC setting following acute hip fracture repair highlights that discharge setting is influenced by clinical vulnerability and social support that may affect subsequent outcomes. As a result, analyses that compare outcomes by discharge setting should account for potential selection bias that arises from the systematic differences in the types of patients who are discharged to different settings.

\section{CONCLUSIONS}

Future research is needed using current data to compare postsurgical morbidity, mortality, and healthcare utilization across these rehabilitation settings to ensure that PAC placement optimizes patient and health system outcomes. Future research should also closely examine factors among veterans discharged directly to home that are predictive of improved postsurgical morbidity and mortality because VHA is serving an increasing caseload of complex patients. With polytrauma, blast injuries, and other conditions central to current conflicts becoming more common in current VA rehabilitation practice, there may be a need to adjust priorities for assigning patients with other conditions to PAC settings. However, this study to identify existing patterns for PAC discharge for a sentinel diagnosis (hip fracture) for which there is not clear evidence to guide decisions is a fundamental step toward a goal of optimal use of limited rehabilitation resources.

\section{ACKNOWLEDGMENTS}

\section{Author Contributions:}

Study concept and design: M. L. Maciejewski, T. A. Radcliff, E. Hutt.

Acquisition of data: T. A. Radcliff, E. Hutt.

Analysis and interpretation of data: M. L. Maciejewski,

T. A. Radcliff, E. Hutt, W. G. Henderson, E. Regan, D. Cowper Ripley, W. B. Vogel.

Drafting of manuscript: M. L. Maciejewski, T. A. Radcliff,

E. Hutt.

Critical revision of manuscript for important intellectual content: W. G. Henderson, D. Cowper Ripley, W. B. Vogel, E. Regan.

Statistical analysis: M. L. Maciejewski, T. A. Radcliff.

Obtained funding: T. A. Radcliff, E. Hutt.

Study supervision: T. A. Radcliff, E. Hutt.

Final approval for submission: M. L. Maciejewski, T. A. Radcliff, W. G. Henderson, D. Cowper Ripley, W. B. Vogel, E. Regan, E. Hutt.

Financial Disclosures: Drs. Maciejewski, Radcliff, Henderson, Cowper Ripley, Vogel, Regan, and Hutt report no financial relationships with relevant commercial entities. Dr. Maciejewski holds shares in Amgen through his spouse's employment.

Funding/Support: This material is based on work supported by the VA Office of Research and Development, Health Services Research and Development Service (grant IIR 04-173). Dr. Maciejewski was supported by a Research Career Scientist award from the VA (grant RCS 10-391).

Additional Contributions: The authors would like to acknowledge the VA SQDUG for its role as scientific advisors and for the critical review of data use and analysis presented in this article. The authors would also like to acknowledge helpful comments from two reviewers and the editor. Research assistance from Elizabeth Shahan and Lauren Pointer is acknowledged.

Institutional Review: This study was approved by the Durham VA Medical Center Institutional Review Board. Human subjects approvals were obtained from the local institutional review boards of each coauthor, and authorization to use VASQIP data was obtained from the VA SQDUG of Patient Care Services in VA Central Office, Washington, DC.

Disclaimer: The views expressed are those of the authors and do not necessarily reflect the views of the VA, Duke University, the University of Colorado Denver, National Jewish Health, or the Texas A\&M Health Science Center. 


\section{REFERENCES}

1. Buntin MB, Colla CH, Escarce JJ. Effects of payment changes on trends in post-acute care. Health Serv Res. 2009;44(4):1188-1210. [PMID:19490159]

http://dx.doi.org/10.1111/j.1475-6773.2009.00968.x

2. Buntin MB, Garten AD, Paddock S, Saliba D, Totten M, Escarce JJ. How much is postacute care use affected by its availability? Health Serv Res. 2005;40(2):413-34.

[PMID:15762900]

http://dx.doi.org/10.1111/j.1475-6773.2005.0i366.x

3. Dejong G, Palsbo SE, Beatty PW, Jones GC, Knoll T, Neri MT. The organization and financing of health services for persons with disabilities. Milbank Q. 2002;80(2):261-301. [PMID:12101873]

http://dx.doi.org/10.1111/1468-0009.t01-1-00004

4. Bass E, French DD, Bradham DD, Rubenstein LZ. Riskadjusted mortality rates of elderly veterans with hip fractures. Ann Epidemiol. 2007;17(7):514-19.

[PMID:17420142]

http://dx.doi.org/10.1016/j.annepidem.2006.12.004

5. Radcliff TA, Henderson WG, Stoner TJ, Khuri SF, Dohm M, Hutt E. Patient risk factors, operative care, and outcomes among older community-dwelling male veterans with hip fracture. J Bone Joint Surg Am. 2008;90(1):34-42. [PMID:18171955] http://dx.doi.org/10.2106/JBJS.G.00065

6. Duncan PW, Horner RD, Reker DM, Samsa GP, Hoenig H, Hamilton B, LaClair BJ, Dudley TK. Adherence to postacute rehabilitation guidelines is associated with functional recovery in stroke. Stroke. 2002;33(1):167-77.

[PMID:11779907]

http://dx.doi.org/10.1161/hs0102.101014

7. Uomoto JM, Williams RM. Post-acute polytrauma rehabilitation and integrated care of returning veterans: Toward a holistic approach. Rehabil Psychol. 2009;54(3):259-69. [PMID:19702424] http://dx.doi.org/10.1037/a0016907

8. Kramer AM, Steiner JF, Schlenker RE, Eilertsen TB, Hrincevich CA, Tropea DA, Ahmad LA, Eckhoff DG. Outcomes and costs after hip fracture and stroke. A comparison of rehabilitation settings. JAMA. 1997;277(5):396-404.

[PMID:9010172] http://dx.doi.org/10.1001/jama.1997.03540290048031

9. Kane RL, Chen Q, Finch M, Blewett L, Burns R, Moskowitz M. Functional outcomes of posthospital care for stroke and hip fracture patients under medicare. J Am Geriatr Soc. 1998;46(12):1525-33. [PMID:9848813]

10. Kane RL, Chen Q, Finch M, Blewett L, Burns R, Moskowitz M. The optimal outcomes of post-hospital care under medicare. Health Serv Res. 2000;35(3):615-61.

[PMID:10966088]
11. Chen Q, Kane RL, Finch MD. The cost effectiveness of post-acute care for elderly Medicare beneficiaries. Inquiry. 2000-2001;37(4):359-75. [PMID:11252446]

12. Chan L. The state-of-the-science: Challenges in designing postacute care payment policy. Arch Phys Med Rehabil. 2007;88(11):1522-25. [PMID:17964899] http://dx.doi.org/10.1016/j.apmr.2007.05.032

13. Buntin MB. Access to postacute rehabilitation. Arch Phys Med Rehabil. 2007;88(11):1488-93. [PMID:17964894] http://dx.doi.org/10.1016/j.apmr.2007.07.023

14. Nguyen-Oghalai TU, Kuo YF, Zhang DD, Graham JE, Goodwin JS, Ottenbacher KJ. Discharge setting for patients with hip fracture: Trends from 2001 to 2005. J Am Geriatr Soc. 2008;56(6):1063-68. [PMID:18422950] http://dx.doi.org/10.1111/j.1532-5415.2008.01688.x

15. Khuri SF, Daley J, Henderson W, Hur K, Demakis J, Aust JB, Chong V, Fabri PJ, Gibbs JO, Grover F, Hammermeister K, Irvin G 3rd, McDonald G, Passaro E Jr, Phillips L, Scamman F, Spencer J, Stremple JF; National VA Surgical Quality Improvement Program. The Department of Veterans Affairs' NSQIP: The first national, validated, outcomebased, risk-adjusted, and peer-controlled program for the measurement and enhancement of the quality of surgical care. Ann Surg. 1998;228(4):491-507. [PMID:9790339] http://dx.doi.org/10.1097/00000658-199810000-00006

16. Daley J, Khuri SF, Henderson W, Hur K, Gibbs JO, Barbour G, Demakis J, Irvin G 3rd, Stremple JF, Grover F, McDonald G, Passaro E Jr, Fabri PJ, Spencer J, Hammermeister K, Aust JB, Oprian C. Risk adjustment of the postoperative morbidity rate for the comparative assessment of the quality of surgical care: Results of the National Veterans Affairs Surgical Risk Study. J Am Coll Surg. 1997; 185(4):328-40. [PMID:9328381]

17. Kane RL, Finch M, Chen Q, Blewett L, Burns R, Moskowitz M. Post-hospital home health care for Medicare patients. Health Care Financ Rev. 1994;16(1):131-53. [PMID:10140151]

18. Neu CR, Harrison SC. Heilbrunn JZ. Medicare patients and postacute care: Who goes where? Santa Monica (CA): Rand Corp; 1989.

19. Manton KG, Woodbury MA, Vertrees JC, Stallard E. Use of Medicare services before and after introduction of the prospective payment system. Health Serv Res. 1993;28(3): 269-92. [PMID:8344820]

20. Steiner A, Neu CR. Monitoring the changes in use of Medicare post-hospital services. Santa Monica (CA): UCLA/ Harvard Center for Health Care Financing Policy Research; 1993.

21. Blewett LA, Kane RL, Finch M. Hospital ownership of post-acute care: Does it increase access to post-acute care services? Inquiry. 1995-1996;32(4):457-67.

[PMID:8567082] 
22. Lane PW, Nelder JA. Analysis of covariance and standardization as instances of prediction. Biometrics. 1982;38(3): 613-21. [PMID:7171691] http://dx.doi.org/10.2307/2530043

23. Bentler SE, Liu L, Obrizan M, Cook EA, Wright KB, Geweke JF, Chrischilles EA, Pavlik CE, Wallace RB, Ohsfeldt RL, Jones MP, Rosenthal GE, Wolinsky FD. The aftermath of hip fracture: Discharge placement, functional status change, and mortality. Am J Epidemiol. 2009; 170(10):1290-99. [PMID:19808632]

http://dx.doi.org/10.1093/aje/kwp266

Submitted for publication February 13, 2013. Accepted in revised form May 24, 2013.
This article and any supplementary material should be cited as follows:

Maciejewski ML, Radcliff TA, Henderson WG, Cowper Ripley D, Vogel WB, Regan E, Hutt E. Determinants of postsurgical discharge setting for male hip fracture patients. J Rehabil Res Dev. 2013;50(9):127-76. http://dx.doi.org/10.1682/JRRD.2013.02.0041

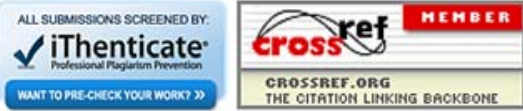

